\title{
Growth Factor for Pigs in Liver Extracts and its Relation to Piglet Anaemia
}

\author{
BY R. BRAUDE \\ National Institute for Research in Dairying, University of Reading
}

(Received 8 August 1949)

Under the conditions in the Shinfield piggery, piglets reared indoors invariably develop anaemia, unless they are given some iron supplement. As a routine, each piglet during its and week of life is dosed with approximately $30 \mathrm{mg}$. of iron daily, given in the form of a solution of iron pyrophosphate.

During recent years evidence has accumulated indicating that, although iron deficiency is the cause of piglet anaemia and hence of the retardation of growth connected with it, there might be other factors involved. Relationship between anaemia and some factors of the vitamin B complex was suggested by a number of workers, and Sebrell (1947) has reviewed the literature on the subject.

As far as pigs are concerned it has been shown that anaemia may develop when the diet is deficient in riboflavin (Wintrobe, Buschke, Follis \& Humphreys, 1944), nicotinic acid (Miller \& Rhoads, 1935), pyridoxin (Wintrobe, Follis, Miller, Stein, Alcayaga, Humphreys, Suksta \& Cartwright, 1943) or pantothenic acid (Wintrobe, Follis, Alcayaga, Paulson \& Humphreys, 1943).

In $x 947$ an investigation was started to study the relationship between iron-deficiency anaemia and the B-complex vitamins. As a source of the B-complex vitamins we used an iron-free liver extract. The liver extract was chosen because it was known to contain all the factors of the vitamin B complex necessary for normal growth and blood formation.

Since then Smith (1948) and Rickes, Brink, Koniuszy, Wood \& Folkers (1948) announced the isolation of a pure anti-pernicious-anaemia factor from the liver, which they named vitamin $B_{12}$. As the present experiments progressed it appeared possible that the active principle involved might be the newly discovered vitamin $B_{12}$, and the search was pursued with this aspect in view. Quite recently, American workers (Johnson \& Neumann, 1948; Neumann, Krider \& Johnson, 1948) reported that piglets showed a marked growth response to anti-pernicious-anaemia liver extracts. It is also of interest that Nichol, Robblee, Cravens \& Elvehjem (1947, 1949) found that concentrated liver preparations used in the therapy of pernicious anaemia were highly active in promoting growth of chicks under standardized conditions.

\section{EXPERIMENTAL}

Pigs and their treatment. The Large White in-pig sows are kept in Shinfield out of doors on grass until about a fortnight before they are due to farrow, when they are put into pens in a Danish-type farrowing house. 
For the purpose of this experiment every litter of pigs born in the piggery was weighed at birth, marked, and a blood sample was taken from the ear vein of each of the piglets. The weighing and blood sampling were repeated when the litter was 4,7 , IO and 14 days old, and then at weekly intervals until weaning, at 8 weeks. The alkaline haematin method (Clegg \& King, 1942) was used for haemoglobin estimation. When the litter was 7 days old comparable groups of four piglets were selected, using weight of the piglet as a criterion, but the whole litter was left on the sow. One piglet in each group was at random allocated to be dosed daily for 7 days during the $2 n d$ week of life according to one of the following four treatments: treatment I, approx. $30 \mathrm{mg}$. iron contained in $2 \mathrm{ml}$. iron-pyrophosphate solution; treatment $2,2.5 \mathrm{ml}$. crude liver extract free of iron; treatment $3,2 \mathrm{ml}$. iron-pyrophosphate solution and $2.5 \mathrm{ml}$. crude liver extract (treatments I and 2 combined); treatment 4 , controls, not dosed. When the piglets were 3 weeks old supplementary food was given in the form of a good suckingpigs' mixture, provided in troughs placed inside the creeps, to which the piglets had access day and night. All the sows and their litters were kept indoors throughout the suckling period.

First experiment. For the first experiment seventeen groups of four piglets each, out of twelve litters were available. For the last five groups an additional, fifth, treatment was added, namely, daily dosing with $2 \mathrm{ml}$. iron-pyrophosphate solution and $5 \mathrm{ml}$. yeast extract. The yeast extract was chosen as it was known to contain most of the B-complex vitamins, but not the anti-pernicious-anaemia factor present in liver. Of this extract I $\mathrm{ml}$. was equivalent to $0.5 \mathrm{~g}$. dried brewer's yeast. It appeared that the $5 \mathrm{ml}$. of yeast extract was more than the pig could comfortably tolerate. As the results with the yeast extract were, to some extent, influenced by the difficulties connected with the dosing with large amounts of liquid, three additional litters were used in this test; they were divided into groups of three piglets only. The three treatments were: iron, iron with liver extract, and iron with $2.5 \mathrm{ml}$. concentrated yeast extract ( $1 \mathrm{ml}$. equivalent to $\mathrm{I} g$. dried brewer's yeast).

Second experiment. In the second experiment the main experimental procedure was repeated with litters reared out of doors. The sows farrowed in the piggery, but when the litters were 7 days old the sows and litters were transferred to portable field units, moved daily on pasture. Blood samples were not collected. Twenty-five groups out of eleven litters were available for this test. It should be noted that in Exps. I and 2 litters born during the winter season were used.

Third experiment. During the summer of 1948 a third experiment was conducted on twenty groups of three litter-mates reared indoors. In addition to a control treatment without supplements two further treatments were used involving daily dosing during the 2nd week of life: (I) with $2 \mathrm{ml}$. iron-pyrophosphate solution; (2) with $2 \mathrm{ml}$. iron-pyrophosphate solution and $2.5 \mathrm{ml}$. Examen (Glaxo Laboratories Ltd.), a concentrated liver extract used for clinical treatment of pernicious anaemia, known to be free from iron and comparatively rich in vitamin $B_{12}$. 


\section{RESULTS}

First experiment. The results are presented in the form of graphs. In Fig. I the average blood-haemoglobin curves are given. It is quite obvious that the normal decline in haemoglobin found in piglets reared indoors was not checked by a supplement of crude liver extract alone. On the other hand, the iron supplement given alone or with

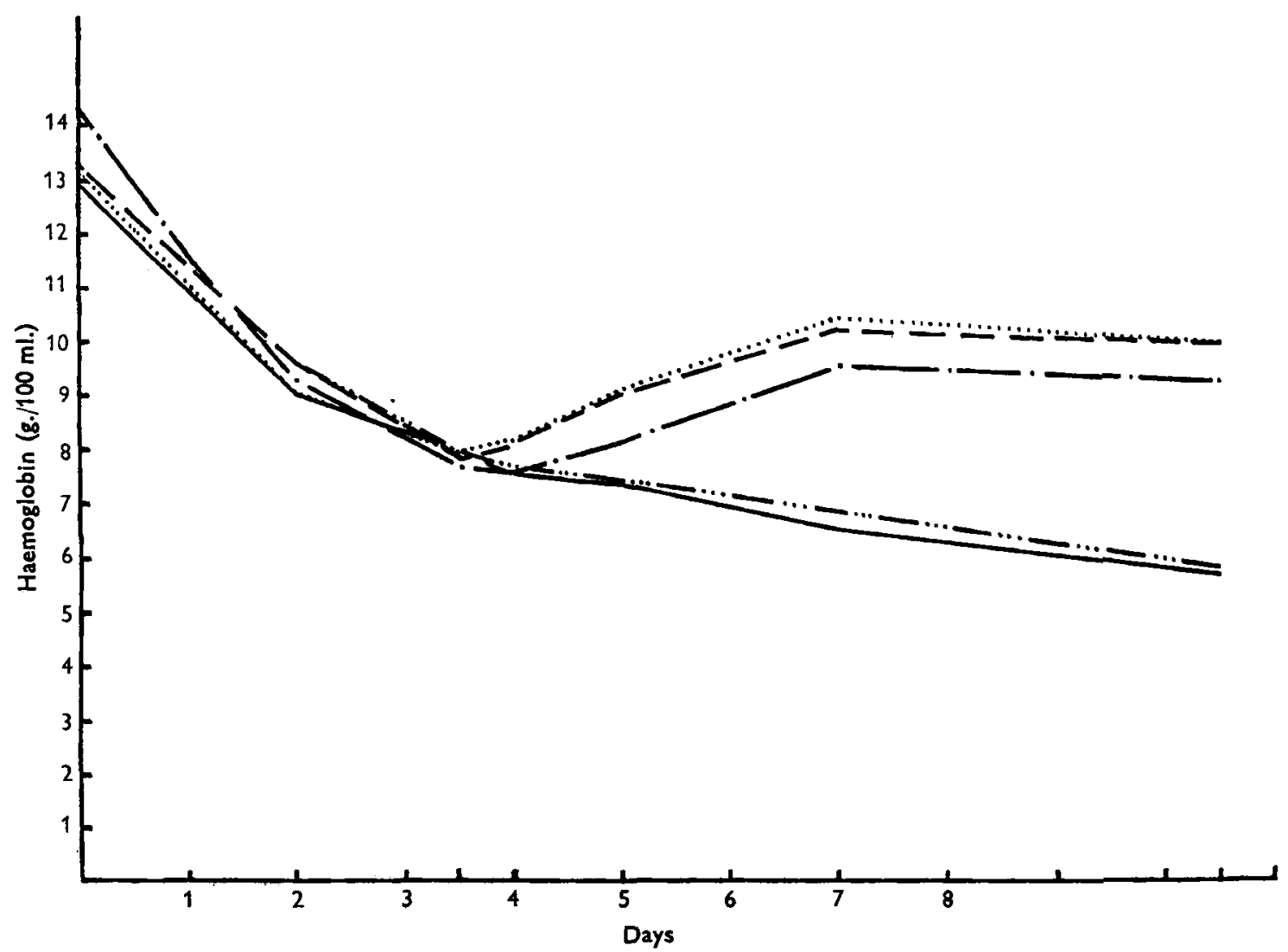

Fig. 1. Exp. I. Average blood haemoglobin values of piglets given the following supplements: -- , iron only $(16) ; \cdots \cdots$, , iron and liver extract $(16) ; \cdots \cdots \cdots-$, liver extract only $(16) ; \cdot \cdots \cdot-\cdot-$, iron and yeast extract (6); - , no supplement (16). The figures in parentheses indicate the number of piglets in the group.

either liver or yeast extract checked the fall in haemoglobin values and brought them back to normal levels. As far as haemoglobin formation is concerned it is obvious that neither liver nor yeast extract had any supplementary effect on this action of iron.

In Fig. 2 the growth curves of the piglets are presented. This graph shows the expected superiority of piglets treated with an iron supplement (treatment $\mathrm{I}$ ) to those which received no iron (treatment 4). Liver extract by itself (treatment 2) had no effect on growth. On each of the treatments 2 and 4 two pigs died before weaning, with symptoms typical of anaemia. However, piglets which received both iron and liver extract (treatment 3 ) grew at a better rate than their litter-mates which received 
iron alone. The average weight at weaning of piglets on treatment 3 was higher by $2.65 \mathrm{lb}$. than that of piglets on treatment $\mathrm{I}$. This corresponds to $1 \mathrm{r} \cdot 8 \%$ of the average weaning weight of the heavier group. Although this difference lacks the conventional statistical significance the data show a definite trend. The main response to the liver

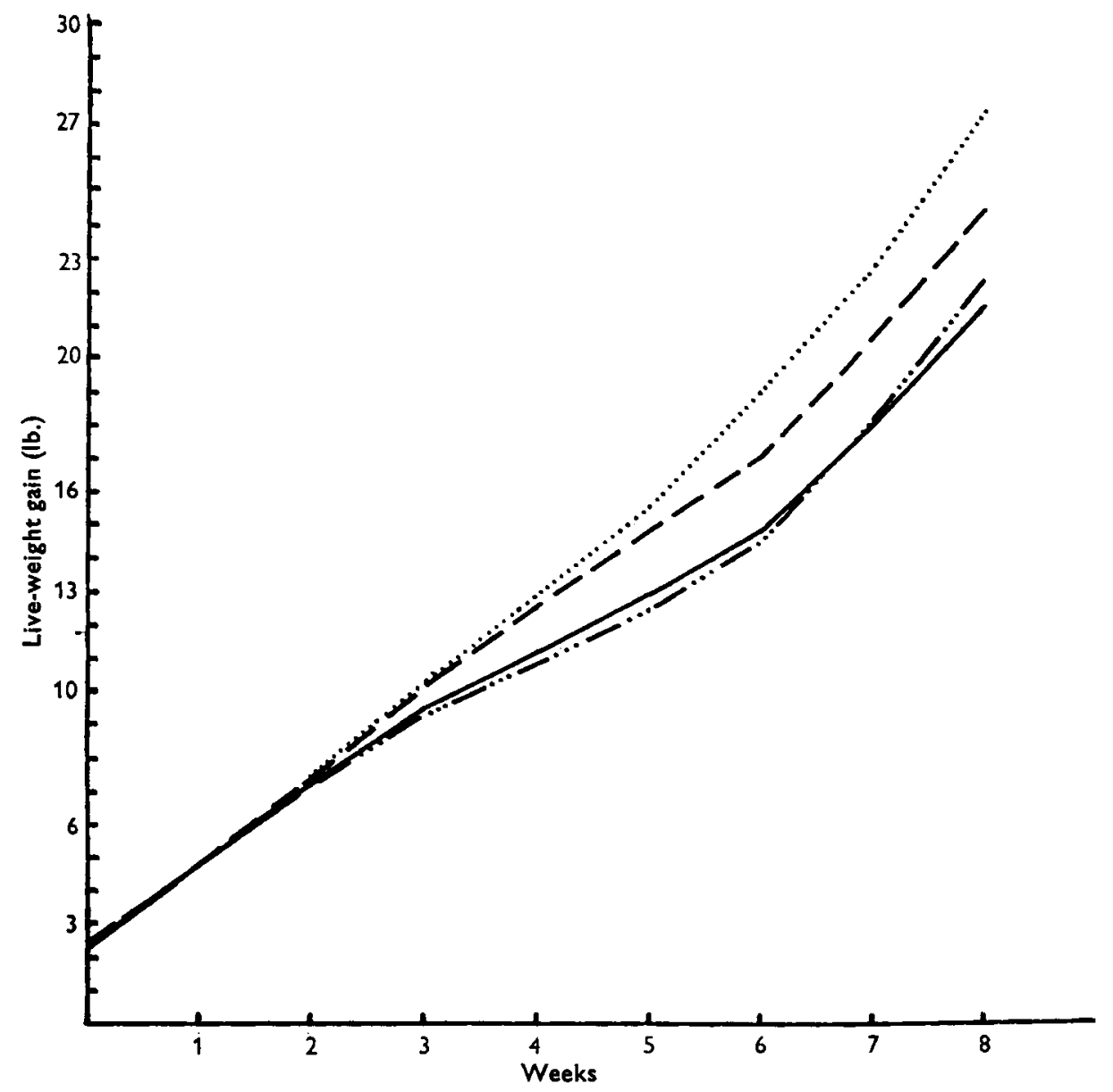

Fig. 2. Exp. I. Main test. Average live-weight gain of piglets reared indoors given the following supplements: $-\cdots$, iron only (17); $\cdots \cdots$, iron and liver extract ( 17 ); $\cdots \cdots \cdots$, liver extract only (15); - no supplement (15). The figures in parentheses indicate the number of piglets in the group.

extract was between the 2nd and $5^{\text {th }}$ or 6 th weeks of life, i.e. during the period of very rapid growth when piglets do not get enough nutrients from sow's milk to satisfy their requirements and begin to supplement it with concentrated food made available to them in the form of a meal.

In Fig. 3 the effect of supplementing iron with liver extract is shown again and contrasted with the lack of effect of yeast extract. The piglets that received $2 \mathrm{ml}$. ironpyrophosphate solution and $5 \mathrm{ml}$. yeast extract obviously suffered from excess of the supplements given at one time. Their rate of growth was below normal, and hence the average growth curve for this group was below that for piglets receiving iron alone. 
However, when $2.5 \mathrm{ml}$. concentrated yeast extract were given there was hardly any difference between the piglets receiving iron alone and those receiving iron together with the yeast extract.

Second experiment. Fig. 4 gives the average growth curves of the piglets. These piglets were reared out of doors and received the same four experimental treatments

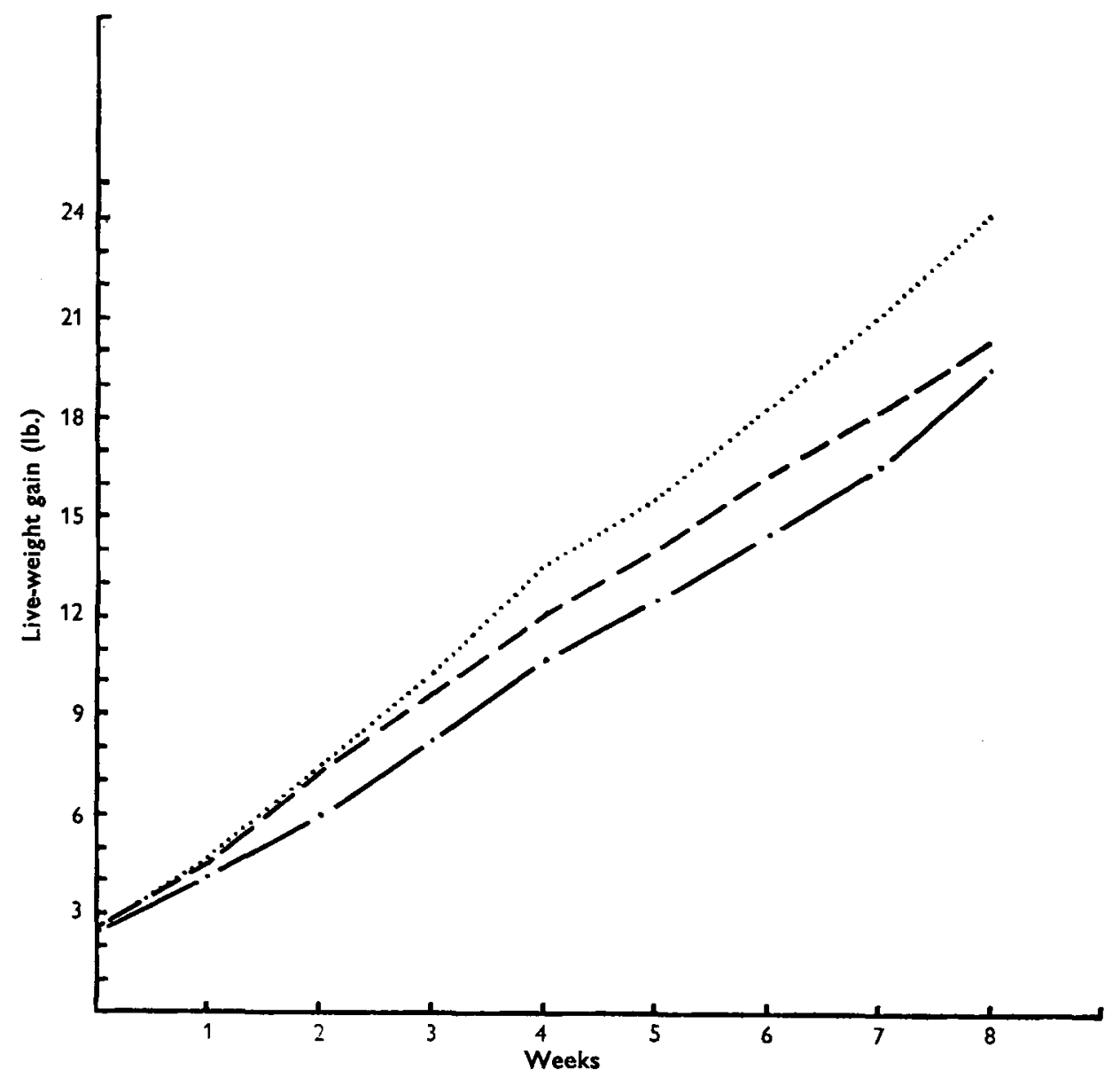

Fig. 3. Exp. I. Additional test. Average live-weight gain of piglets reared indoors which received the following supplements: --- , iron only (IO); $\cdots \cdots$, , iron and liver extract (10); .-.-, iron and yeast extract (10). The figures in parentheses indicate the number of piglets in the group.

as given to piglets reared indoors in Exp. I. It is interesting to note that none of the supplements had any beneficial effect. The piglets on treatment 4 , without any supplement, were obviously able to satisfy all their requirements for iron from what they could gather on pasture. The rate of growth of the piglets reared out of doors was considerably better than that of those reared indoors. Only the piglets that, during the winter indoor experiment, received both iron and liver extract supplement grew at a rate anywhere approximating that of the piglets kept out of doors, but even their average weaning weight was $3.4 \mathrm{I} \mathrm{lb}$. less than the average for all the pigs kept out of doors (equivalent to $12.5 \%$ of this average). It is well recognized in agricultural 
practice that piglets reared out of doors grow better than those kept indoors. Probably the liver supplement given together with iron made up to some extent the deficiency connected with indoor rearing of piglets.

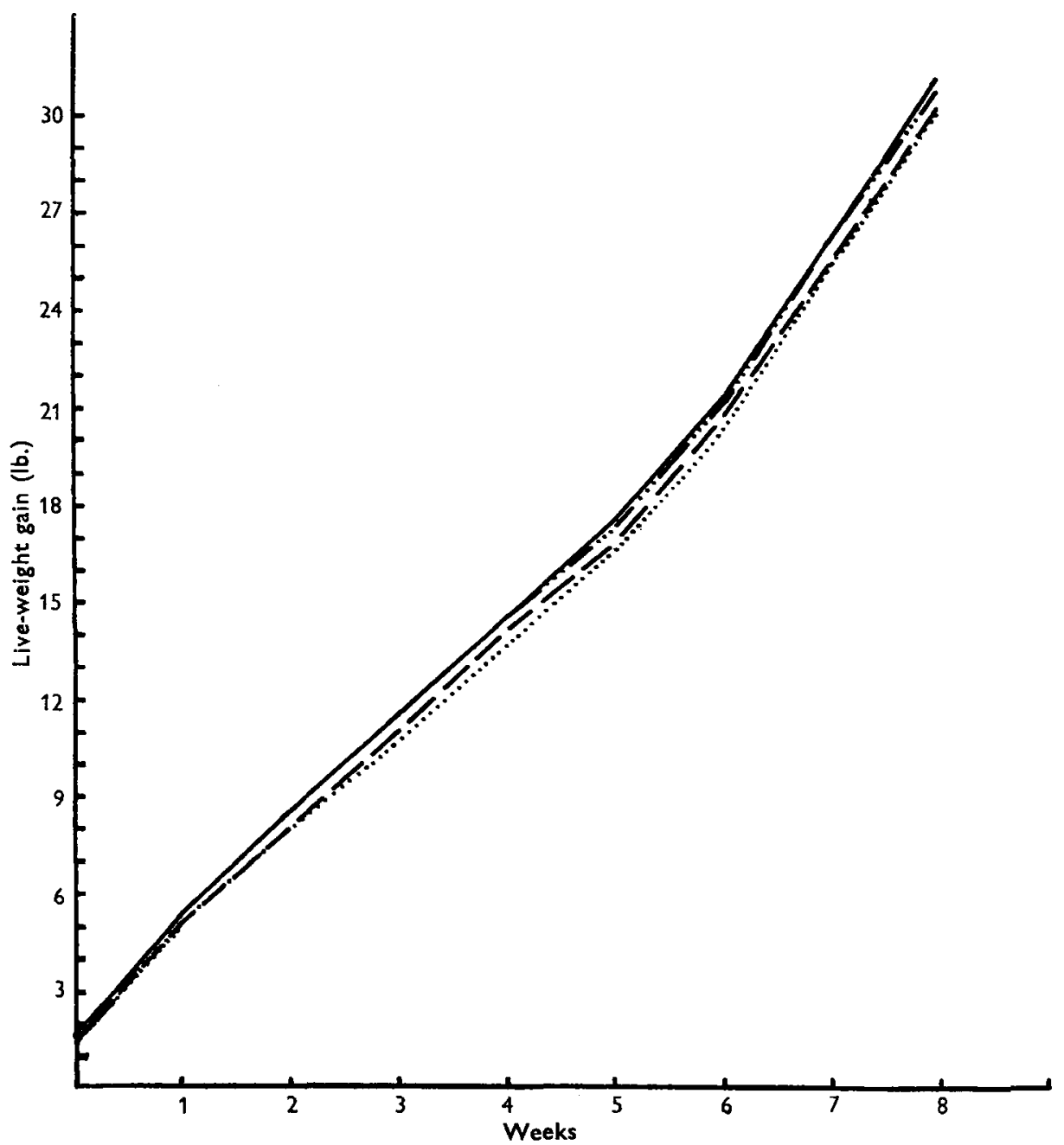

Fig. 4. Exp. 2. Average live-weight gain of piglets reared out of doors given the following supplements: --- , iron only $(26) ; \cdots \cdots$, , iron and liver extract $(24) ; \cdots-\cdots-$, liver extract only $(25) ;-$, no supplement (23). The figures in parentheses indicate the number of piglets in the group.

Third experiment. The results are summarized in Fig. 5. Again, the effect of iron supplement is quite obvious. Two piglets in the control group receiving no supplement died before reaching the weaning time, and others showed symptoms of anaemia. The piglets that received iron and Examen grew, on the average, at a better rate than those receiving iron alone, but the recorded difference was smaller than that in Exp. I. It amounted to only $0.79 \mathrm{lb}$., or $2.9 \%$ of the average of the heavier group. Unfortunately, the average weaning weight of the piglets receiving iron and Examen was reduced by the performance of three piglets which, for unknown reasons, did very poorly. 


\section{DISCUSSION}

The very great individual variation between piglets from the same litter in their susceptibility to anaemia, or possibly to the secondary effects associated with anaemia, is a characteristic feature of all our work on piglet anaemia and still needs explanation.

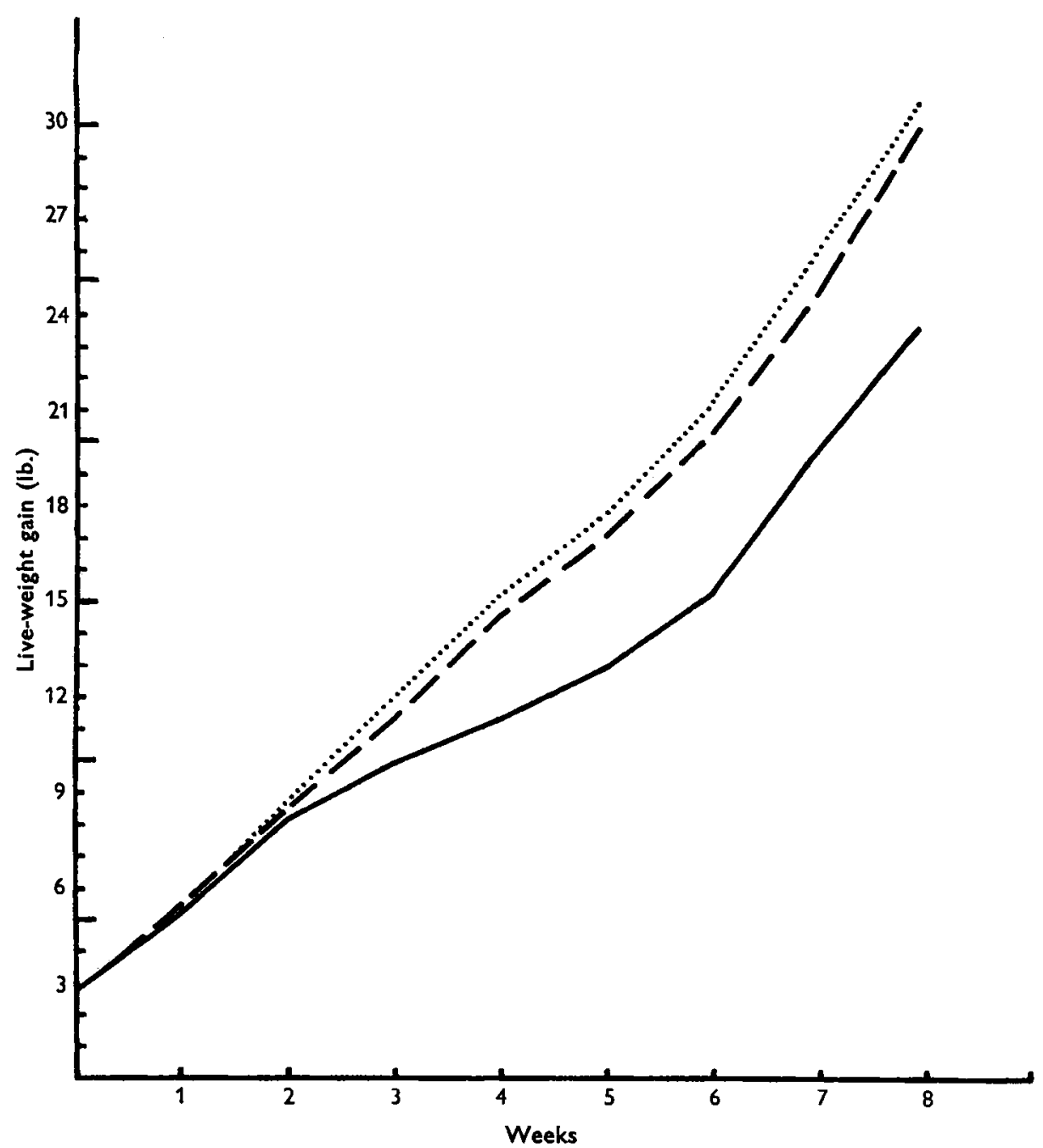

Fig. 5. Exp. 3. Average live-weight gain of piglets reared indoors given the following supplements: - - , iron only $(20) ; \cdots \cdots$, , iron and Examen (a concentrated liver extract, prepared by Glaxo Laboratories Ltd.) (20); - no supplement (18). The figures in parentheses indicate the number of piglets in the group. Note. Piglets in Exp. 3, born in summer, grew at a better rate than those in Exp. I, born in winter, which received similar treatment. It is well known in agricultural practice that litters born in summer grow better than those born in winter.

There can be no doubt that iron deficiency was the primary factor involved. However, piglets that received iron supplement grew sometimes at a very slow rate for no obvious reason. It also happened that piglets that received no iron supplement, and were expected to develop anaemia, grew quite normally during the whole suckling 
period, and sometimes even at a rate above the normal. On some occasions some untreated piglets in one litter succumbed to anaemia, whereas others showed no ill effects whatsoever.

An interesting observation was recently reported from Norway (Dedichen, 1949). There pigs' livers collected during the winter months were almost devoid of antipernicious-anaemia activity, whereas those collected in summer months from pigs kept out of doors had high activity. This observation falls in line with the results of experiments reported here. In the first experiment, carried out during the winter, the piglets responded well to a factor present in a liver supplement; during the summer, piglets kept out of doors did not respond at all.

The response of piglets reared indoors during the winter to the dosing with crude liver extract, the lack of response to yeast extract, and the lack of response from piglets reared out of doors in summer, supported by the findings of Dedichen (1949), justify the speculation that the growth factor involved is the recently isolated vitamin $B_{12}$, or an entity closely associated with it. Experiments to substantiate this hypothesis are in progress.

\section{SUMMARY}

I. Piglets reared indoors and given during their 2nd week of life a supplement of liver extract grew on the whole at a better rate than their control litter-mates.

2. The beneficial effect of the liver extract was manifested only when it was given together with an iron supplement to prevent anaemia.

3. Yeast extract had no similar growth-promoting effect.

4. The liver extract had no effect, however, on the growth rate of piglets reared out of doors.

5. The liver extract had no effect on the blood picture of the piglets, as measured by haemoglobin values.

I wish to thank Dr T. F. Macrae and Dr E. Lester Smith of Glaxo Laboratories Ltd., Greenford, Middlesex, for the supply of the liver and yeast extracts. I also wish to acknowledge with thanks the help received from Miss E. Henriques and Mr K. G. Mitchell.

\section{REFERENCES}

Clegg, J. W. \& King, E. J. (1942). Brit. med. F. ii, 329.

Dedichen, J. (1949). Lancet, 256, 369 .

Johnson, B. C. \& Neumann, A. L. (1948). F. Anim. Sci. 7, 528.

Miller, D. K. \& Rhoads, C. P. (1935). F. clin. Invest. 14, 153.

Neumann, A. L., Krider, J. L. \& Johnson, B. C. (1948). Proc. Soc. exp. Biol., N.Y., 69, 513.

Nichol, C. A., Robblee, A. R., Cravens, W. W. \& Elvehjem, C. A. (1947). F. biol. Chem. 170, 419.

Nichol, C. A., Robblee, A. R., Cravens, W. W. \& Elvehjem, C. A. (I949). F. biol. Chem. I77, 631.

Rickes, E. L., Brink, N. G., Koniuszy, F. R., Wood, T. R. \& Folkers, K. (1948). Science, ro8, 134.

Sebrell, W. H. (1947). The vitamin B complex and anaemia. In Symposia on Nutrition, vol. 1, p. 164. [Arthur Lejwa, editor.] Cincinnati, Ohio: The Robert Gould Research Foundation Inc.

Smith, E. L. (1948). Nature, Lond., 161, $63^{8}$.

Wintrobe, M. M., Buschke, W., Follis, R. H. Jr. \& Humphreys, S. (1944). Fohns Hopk. Hosp. Bull. 75, 102 .

Wintrobe, M. M., Follis, R. H. Jr., Alcayaga, R., Paulson, M. \& Humphreys, S. (1943). Johns Hopk. Hosp. Bull. 73, 3 I3.

Wintrobe, M. M., Follis, R. H. Jr., Miller, M. H., Stein, H. J., Alcayaga, R., Humphreys, S., Suksta, A. \& Cartwright, G. E. (1943). Fohns Hopk. Hosp. Bull. 72, I. 